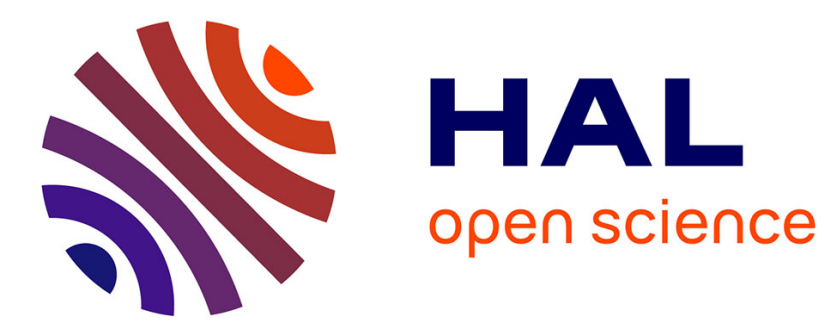

\title{
The mechanics of membrane proteins is a signature of biological function
}

Felix Rico, Laura Picas, Adai Colom, Nikolay Buzhynskyy, Simon Scheuring

\section{To cite this version:}

Felix Rico, Laura Picas, Adai Colom, Nikolay Buzhynskyy, Simon Scheuring. The mechanics of membrane proteins is a signature of biological function. Soft Matter, 2013, 9, pp.7866-7873. $10.1039 / \mathrm{c} 3 \mathrm{sm} 50967 \mathrm{~b}$. inserm-01309103

\section{HAL Id: inserm-01309103 https://www.hal.inserm.fr/inserm-01309103}

Submitted on 28 Apr 2016

HAL is a multi-disciplinary open access archive for the deposit and dissemination of scientific research documents, whether they are published or not. The documents may come from teaching and research institutions in France or abroad, or from public or private research centers.
L'archive ouverte pluridisciplinaire HAL, est destinée au dépôt et à la diffusion de documents scientifiques de niveau recherche, publiés ou non, émanant des établissements d'enseignement et de recherche français ou étrangers, des laboratoires publics ou privés. 


\title{
The mechanics of membrane proteins is a signature of biological function
}

\author{
Felix Rico ${ }^{\mathrm{a}}$, Laura Picas ${ }^{\mathrm{b}}$, Adai Colom ${ }^{\mathrm{a}}$, Nikolay Buzhynskyy ${ }^{\mathrm{a}}$, and Simon Scheuring ${ }^{\mathrm{a} *}$ \\ Received (in $X X X, X X X)$ Xth $X X X X X X X X X 20 X X$, Accepted Xth $X X X X X X X X X 20 X X$ \\ ${ }_{5}$ DOI: 10.1039/b000000x
}

\begin{abstract}
Beyond structure, the mechanics of plasma membrane components is of key importance to biological function. Nanoscale mechanics is however poorly described due to a lack of suitable experimental tools. Here, we combined atomic force microscopy and nanomechanical mapping to analyze structure and mechanical properties of native eye lens cell membranes. Lens membranes mainly comprise two proteins; 10 aquaporin- 0 and connexin, forming respectively thin and gap intercellular junctions that sustain mechanical stress during accommodation. Our results reveal the mechanical heterogeneity of the plasma membrane, allowing examination of the mechanical nanoenvironment of individual proteins and the flexibility of supramolecular assemblies. The remarkable rigidity of gap junctions suggests their role as stable intercellular adhesion complexes assuring maintenance of thin junctions, which form more flexible 15 supramolecular complexes capable of sustaining pressure differences between cells. Our work proposes the mechanical properties of individual proteins and protein domains directly related to biological function as a novel molecular signature.
\end{abstract}

\section{Introduction}

The plasma membrane is a selective physico-chemical barrier that 20 mediates specific communication between the cell and the extracellular space; and it is often described as a two-dimensional fluid bilayer formed by lipids, cholesterol, sugars and proteins enthrallingly arranged ${ }^{1}$. In conjunction with the different types of receptors, cell adhesion molecules provide mechanical contact

25 between the cell interior and the extracellular matrix or neighbour cells, while membrane transporters and channels allow the exchange of metabolites, water, ions and macromolecules ${ }^{2-4}$. Due to the lack of appropriate tools for mechanical mapping at the nanometer scale, the mechanical properties of individual 30 membrane proteins and supramolecular assemblies has been systematically overseen until recent AFM-based developments ${ }^{5-}$ 11. However, the mechanical properties of the membrane components and their nanoenvironment provide fundamental information related to function, since this is the scale at which the 35 membrane works. For example, the mechanical stability of supramolecular protein complexes is important in cell adhesion and force transduction ${ }^{12}{ }^{13}$, membrane mechanics directly influences the functionality of membrane channels ${ }^{14}$, and flexibility of individual proteins and protein subdomains is 40 required for conformational changes that modulate biological function $^{15}$.

The eye lens is a highly specialized tissue formed by multiple layers of the so-called fiber cells ${ }^{16}$. To assure transparency, fiber ${ }_{45}$ cells require exceptionally narrow intercellular spacing. Additionally, the process of accommodation allows the eye to focus at various distances and is assured by the elasticity of the eye lens. Hence, the intercellular junctions between the plasma membranes of adjacent fiber cells must comply with two ${ }_{50}$ functional tasks: narrow cell-cell contact and mechanical integrity of the tissue during deformation. Two major proteins are present in the plasma membrane: connexins $(\mathrm{Cx})$ hexamers (connexons) and aquaporin 0 (AQP0) tetramers ${ }^{17}$. The extracellular loops of both proteins interact homotypically between adjacent cells to 5 form intercellular channel-junctions. The supramolecular organization of AQP0 and $\mathrm{Cx}$ in the lens plasma membrane has been extensively studied from both healthy and cataract tissue using electron and atomic force microscopy ${ }^{18-20}$. These studies revealed AQP0 and connexons assembled in clusters of several 60 adjacent protein repeats forming, respectively, thin junctions of AQP0 tetramers ordered in a square lattice and gap junctions of closely packed connexons. In addition, and possibly due to the interaction between $\mathrm{Cx} 50$ with $\mathrm{AQP} 0$, thin and gap junctions colocalized forming junctional microdomains ${ }^{19}$, 21 . It has been ${ }_{65}$ suggested that deficient organization of junctional microdomains has a direct implication in the development of senile and type-II diabetes cataracts ${ }^{22}$. While a dual role of AQP0 as adhesion molecule and intercellular water pore is still matter of debate ${ }^{23-25}$, recent works indicate that, in addition to the known channelling 70 function, neuronal connexins play a role as adhesive molecules able to bear significant forces ${ }^{26-28}$. Thus, AQP0 and Cx may play an important adhesive role to assure the mechanical integrity and tight cell-cell binding in the eye lens. Regardless of the well known supramolecular architecture of junctional microdomains, 75 little is known about their mechanical properties, which is important for the proper chemical and physical intercellular communication that ensures tissue integrity. Here we report the direct mechanical mapping of intact membranes from nuclear fiber cells of the eye lens using PeakForce atomic force 80 microscopy (AFM). Our measurements reveal the rich mechanical heterogeneity of the plasma membrane identifying the flexibility of the different membrane components and microstructures. The combination of topographical images and elasticity maps provides evidence of direct contact between ${ }_{85} \mathrm{AQP0s}$ of apposing membranes. The remarkable rigidity of connexin gap junctions and the relative compliance of AQP0 junctional microdomains suggest that gap junctions play a major 
role as rigid and stable adhesion complexes that assure the structural stability of junctional microdomains and the proper contact between eye lens cells, while AQP0 microdomains comply to inter-cell pressure differences.

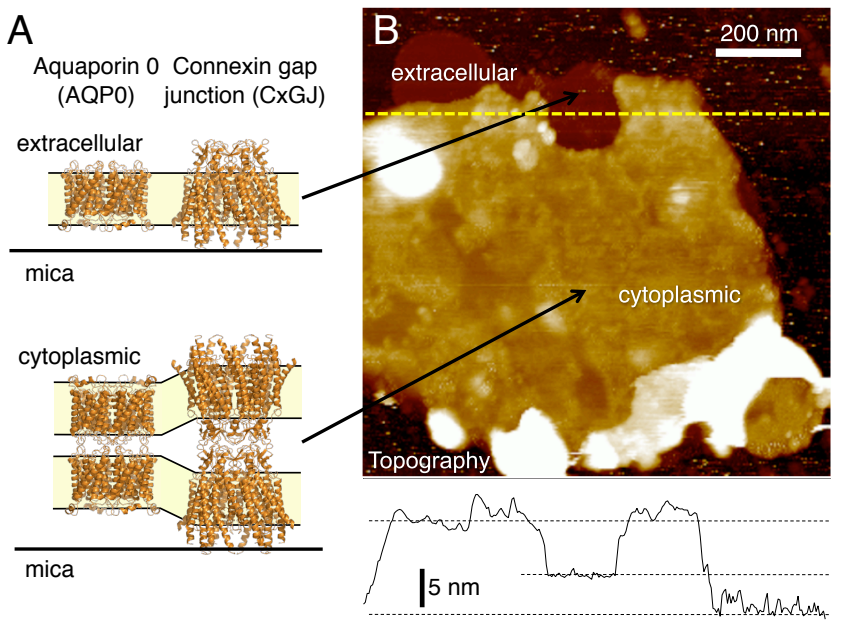

Fig. 1) Isolated plasma membranes from the eye lens maintain the native double-layered architecture. A) Crystal structure representation of the lens membrane proteins connexin and aquaporin 0 , showing single

layer configuration (exposing the extracellular side) and the native, double layer configuration (exposing the cytoplasmic side) (PDB codes $2 \mathrm{ZW} 3$ and $2 \mathrm{~B} 6 \mathrm{O}^{40,41}$. Structural images rendered using Pymol, http://www.pymol.org). B) Overview topography of an isolated lens membrane revealing a darker, single layer region and a brighter, double 15 layer region. The line graph shows the cross section along the dotted line in the image and reveals the thickness of the single and double layers. The false color scale was $25 \mathrm{~nm}$.

\section{Results}

Isolated lens membranes maintain their double layer 20 structure

We used AFM in PeakForce mode to map the topography and mechanical properties (elasticity and deformation) of native membranes isolated from nuclear eye lens cells. In PeakForce mode, the tip oscillates relative to the sample acquiring, at each 25 pixel, a force-distance curve from which topography, elasticity (Young's modulus, E) and deformation is determined (Fig. S1). The lateral forces in PeakForce mode are negligible and allowed us to obtain images of isolated lens membranes deposited on mica without disrupting their native double-layered supramolecular 30 organization (Fig. 1). Figure 1 shows an example of an intact double layer membrane with a region of single layer, with thicknesses ranging between $12 \mathrm{~nm}$ and $16 \mathrm{~nm}$ and between $5 \mathrm{~nm}$ and $9 \mathrm{~nm}$, respectively.

Figure 2 reveals the crowded composition of lens membranes, ${ }_{35}$ presenting ordered AQP0 square arrays surrounded by densely packed connexons and lipid regions. High-resolution images of that same membrane allowed us to distinguish individual AQP0 tetramers in 2D square arrays $(a=b=6.5 \pm 0.2 \mathrm{~nm}, \mathrm{n}=78)$, as well as ring-shaped structures of $5.9 \pm 0.5 \mathrm{~nm}$ in diameter and with an 40 average intermolecular spacing of $8.7 \pm 2.8 \mathrm{~nm}$ characteristic of connexons ( $\mathrm{n}=14$, Fig. 3$)^{19}$. Previous images of lens cells junctions using electron microscopy are in agreement with our reported thickness values for both thin and gap junctions and its single layered subcomponents ${ }^{18}$. Given that most of the 45 membrane fragment was intact (double layer), the top layer exposed the cytoplasmic face (CP) and the bottom layer is attached to the support also with the $\mathrm{CP}$, the two layers sandwich the extracellular faces (EC) that are exposed in some particular areas (Fig. 1B and 2A). The low stability of the top layer made it ${ }_{50}$ difficult to identify the different types of proteins from their topographical signature viewed from the CP. However, we were able to observe on the $\mathrm{CP}$ top layer a square periodic signature with a periodicity of $6.7 \pm 0.3 \mathrm{~nm}$, characteristic of AQP0 arrays (Fig. 3) and sometimes ring-like structures interpreted as ${ }_{55}$ connexons. Dissection of the top layer ${ }^{29}$ using contact mode at moderately increased forces $(\geq 200 \mathrm{pN})$ and subsequent contact mode imaging confirmed these assignments (Fig. 2D). It is remarkable that the lattice orientation of APQ0 domains of the top layer matches that of the bottom layer analyzed after 60 dissection, revealing inter-membrane interaction of EC loops of $\mathrm{AQP} 0$, as previously shown on reconstituted $2 \mathrm{D}$ crystals ${ }^{23,30}$.

\section{The plasma membrane of lens cells is mechanically} heterogeneous

Mechanical mapping of supported single- and double-layered 65 lens membranes, exposing the EC and $\mathrm{CP}$ face respectively, revealed rich mechanical heterogeneity. As shown in figure $2 \mathrm{~B}$, EC components (bottom layer) appeared in general stiffer than $\mathrm{CP}$ ones (top layer), being protein regions always stiffer than lipids, and the mica substrate showing saturating $E$ values. While

70 topographic images of the top layer allowed only visualization of faint AQP0 lattice characteristics of thin junctions and rarely ring like structures (Fig. 3), we obtained clear mechanical contrast of the various membrane components on both layers. This contrast allowed us to recognize the different molecular species and 75 calculate average values of mechanical properties for the EC and $\mathrm{CP}$, protein and lipid regions. Indeed, on the $\mathrm{EC}$ face, connexon domains had a similar elastic modulus $(60 \pm 17 \mathrm{MPa}$, mean \pm standard deviation) than AQP0 domains ( $58 \pm 22 \mathrm{MPa})$, being both stiffer than lipids (26 $\pm 8 \mathrm{MPa})$. The CP face of fully formed gap 80 junction domains was softer $(51 \pm 12 \mathrm{MPa})$ than their corresponding $\mathrm{EC}$ face. AQP0s appeared much more compliant at

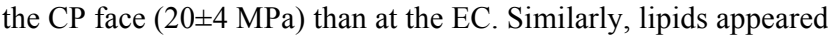
softer when probed on the $\mathrm{CP}$ surface $(8 \pm 2 \mathrm{MPa})$ than on the EC (Fig. 4). It is important to note that the Young's modulus values 85 of the different membrane components extracted from CP side are only reliable in the case of $\mathrm{Cx}$ domains, since these are the thicker structures and thus the only ones in direct contact with the mica substrate. The CP AQP0 thin junction and lipid domains were only supported by the edges, thus the Young's moduli 90 provide only a qualitative estimate of the flexibility of these structures, as discussed below. Recent work using PeakForce at various applied forces on DOPC/DPPC lipid mixtures reported elasticity values of $19 \mathrm{MPa}$ and $28 \mathrm{MPa}$, for fluid and gel phases respectively ${ }^{8}$, which is in good agreement with our observed lipid ${ }_{95}$ elasticity of the EC face. The observed lipid elasticity suggests that the EC leaflet of lens membranes may have an important content of cholesterol, which is known to increase the bilayer stiffness. 

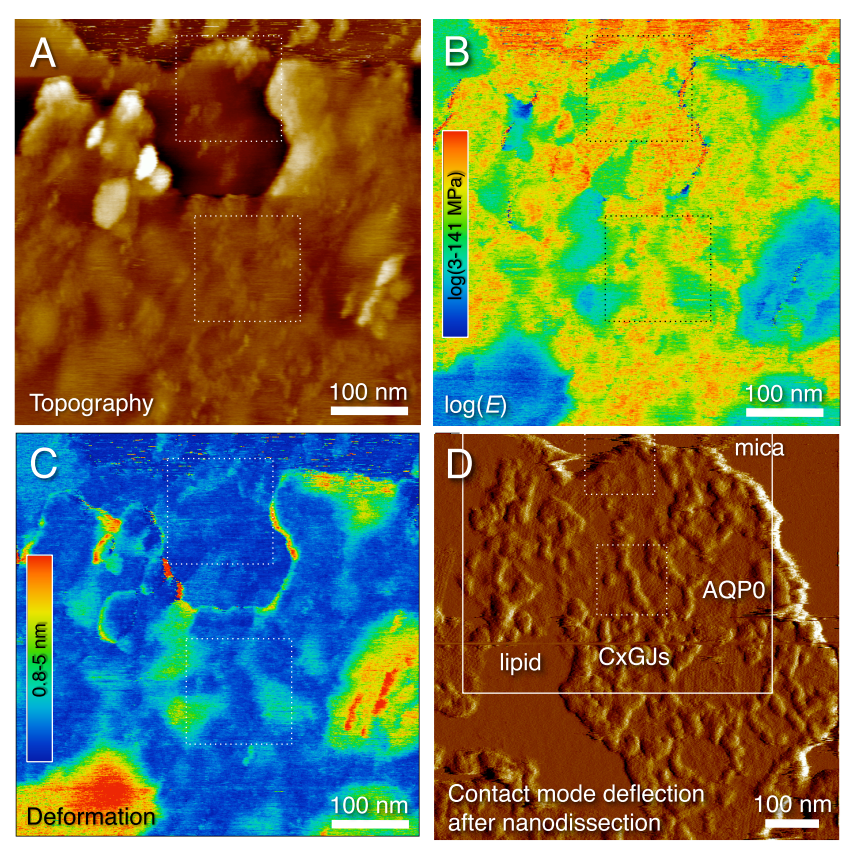

Fig. 2) Mechanical heterogeneity of the plasma membrane of lens cells. A) Topography, B) Young's modulus and C) deformation of double and single-layered lens membrane. D) Contact mode deflection image of the bottom layer after nanodissection. False color scale were $11 \mathrm{~nm}$ (A) and $1.1 \mathrm{~nm}$ (D). Dotted squares represent the regions showed in Fig. 3.

\section{The deformability of AQP0 thin junctions depends on their size}

The force applied during AFM imaging may deform importantly 10 a soft sample. PeakForce imaging allows the deformation to be controlled, measured and assessed at every pixel. We, thus, computed the "undeformed" im-ages by adding the deformation data. While the overall thickness measured from undeformed topography differed only by $\sim 1 \mathrm{~nm}$ relative to the mica substrate 15 com-pared to deformed ones, some regions showed larger deformations. This was particularly noticeable on large lipid and AQP0 domains of the top layer (Suppl. Fig. S2). Remarkably, the deformation of AQP0 thin junctions in-creased with domain diameter (Figs. 4B and S2F).

\section{${ }_{20}$ Mechanical properties of individual AQP0, con-nexons and associated lipids}

To obtain detailed insight into the mechanical proper-ties of the individual proteins and protein-associated lip-ids we used masks to select APQ0 or Cx regions. We then fitted bimodal Gaussian 25 functions corresponding to the two main elasticity populations of the masked regions, i.e. proteins and protein-associated lipids (see Methods section, Fig. 3 and supplementary Fig. S3). While average values report about the elasticity of the whole protein domain, the values obtained from the fitted distributions reflect 30 the elasticity of the individual proteins and the lipids associated to that particular protein. The final elasticity values are shown in table 1. While the stiffness values of the individual proteins were similar to those of the protein domains, the stiffness of the lipids was systematically higher, especially on the cytoplasmic face,

35 than that obtained from the average of pure lipid regions. This could be due to two main reasons. First, different species of lipids surround the protein, and/or second, proteins enhance the mechanical stability of the associated lipids by acting as stable supports.

40 Additionally, the relative area under the fitted bimodal distribution of the $\log (E)$ histograms provided us with an estimate of the ratio of protein/lipid concentration in each protein domain. On both $\mathrm{EC}$ and $\mathrm{CP}$ faces, $\mathrm{AQP} 0 /$ lipid area ratios were $\sim 4$. Connexon regions, in contrast, re-vealed area ratios of $\sim 9$ and $45 \sim 49$ on the EC and CP faces, respectively.

\section{Discussion}

This study uncovers a fundamental feature of the plasma membrane of living cells by revealing the rich mechanical heterogeneity of its individual structural components, not only at so the nanoscale but also at the larger scale of supramolecular assembly. We probed the mechanical properties of the plasma membrane of nuclear fiber cells from the eye lens, as a relevant example of the crowded microenvironment found in the membrane of living cells that is exposed to physiological 55 mechanical stress.

The low lateral forces of PeakForce AFM imaging prevented the disruption of the native double-layered architecture of isolated membranes, allowing a detailed study in a native-like configuration. An important observation of this work is that ${ }_{60}$ AQP0 lattices have the same orientation in the CP and EC surfaces (Figs. 2, 3 S5), implying interaction between apposing AQP0s and then formation of membrane junctions. This allowed us to hypothesize about the formation of domains in the lens membranes. Although the possibility of lateral phase separation ${ }_{65}$ due to lipid mediated protein-protein interaction is plausible, given the reported evidence that lens membrane protein domains assemble during the lifespan of the organism ${ }^{31}$, adhesion induced domain formation is perhaps more probable. We suggest that randomly distributed $\mathrm{AQP} 0$ and $\mathrm{Cx}$ of one cell interact 70 homotypically with the apposing cell at the early stages of cell differentiation. As has been suggested before ${ }^{32,33}$, the different extend of EC domains and binding strength of the two protein species provides an energetically favourable context to form clusters and reorganize spontaneously into differentiated 75 domains, in turn favouring the formation of more complexes. Thus, the supramolecular assembly of lens membranes may form after and as a consequence of the homotypic adhesion of AQP0 and $\mathrm{Cx}$ between apposing cells.

Elasticity maps showed lipids having clearly different mechanical 80 signatures than AQP0 thin junctions and connexin gap junctions in the EC face; and revealing gap junctions more rigid and less deformable than thin junctions and lipid domains in the $\mathrm{CP}$ face (Figs. 2B, 2C and 4A). The Young's moduli for the EC face ranged from $26 \mathrm{MPa}$ for lipid to $60 \mathrm{MPa}$ for connexon domains. ${ }_{85} \mathrm{We}$ calculated the expected bending stiffness $\left(\kappa_{c}\right)$ of the lipid domains with the values of the Young's modulus $(E=58 \mathrm{MPa})$ and the bilayer thickness $(h=4.5 \mathrm{~nm})$ and using the formula $\kappa_{c}=E h^{3} / 24\left(1-v^{2}\right.$ ), proposed by Rawicz et al. ${ }^{34}$ (where $v=0.5$ is the Poisson ratio, see SI). The resulting bending stiffness of ${ }_{90} \sim 32 k_{\mathrm{B}} T$ is in excellent agreement with values of $30-40 k_{\mathrm{B}} T$ reported from flicker spectroscopy experiments on unilamellar lipid vesicles containing 20-30\% cholesterol (being $k_{\mathrm{B}}$ the Boltzmann constant and $T$ room temperature $)^{35}$, similar to the concentration found in lens membranes ${ }^{36}$. As we reported before ${ }_{95}$ on supported lipid bilayers ${ }^{8}$, this remarkable coincidence of the values of the bending stiffness obtained from such different 
experimental methods confirms the negligible contribution of the underlying substrate and the quantitative nature of the measured elastic moduli. Following a similar rationale, we estimated the bending stiffness of lipid, AQP0 and Cx single and double layers 5 resulting in values that span over two orders of magnitude, from the $32 k_{\mathrm{B}} T$ of the single lipid bilayer, through the $1560 k_{\mathrm{B}} T$ of double AQP0 layers, to the $3316 k_{\mathrm{B}} T$ of double $\mathrm{Cx}$ layers (see table S1). These results further highlight the remarkable mechanical heterogeneity of the plasma membrane, revealing $\mathrm{Cx}$ 10 gap junctions as remarkably rigid structures.

As observed in previous studies, AQP0 domains were frequently surrounded by connexons (Figs. 2, 4 and S4). The calculation of deformation corrected images revealed large thin junctions $(>100$ $\mathrm{nm}$ in diameter) protruding above the gap junction plane, ${ }_{15}$ although being structurally thinner (Fig. S2) ${ }^{18}$. This suggested two possibilities for the organization of large thin junctions. Either AQP0 tetramers from the two layers were not in contact, thus, not forming actual junctions, or the observed thin junctions were not in contact with the underlying mica substrate, but

20 floating in the buffer and only sustained by the surrounding more stable and supported $\mathrm{Cx}$ dodecamers. Our data showed that AQP0 from apposing layers interact with each other. We suggest then that in lens membrane fragments deposited on mica, double-layer thin junctions were only sustained by the surrounding gap 25 junctions and not in direct contact with the mica substrate, resulting in bending AQP0 domains. Small thin junction domains appeared less deformable than large ones (Figs. 3, 4 and S2C). Indeed, detailed analysis revealed that the deformation of AQP0 thin junctions increased with the size of the domain (Figs. 4B and

${ }_{30} \mathrm{~S} 2 \mathrm{~F}$ ). The maximum deformation of AQP0 thin junctions as a function of the diameter was well modelled as an elastic thin plate clamped at the perimeter and loaded at the centre with the imaging force applied (Fig. 4B, solid line $)^{37}$. The measured deformation is remarkably well described by this simple model

35 without any fitting parameters, further confirming that our measurements are self-consistent.

The molecular interaction between EC Cx loops has been shown to withstand important pulling forces, while the interaction between EC AQP0 loops, only mediated by hydrophobic 40 contacts, is expected to be weaker ${ }^{25,}{ }^{28}$. Our mechanical data suggests that gap junctions provide rigid $\left(\kappa_{\mathrm{c}}=3316 k_{\mathrm{B}} T\right.$, table $\left.\mathrm{S} 1\right)$ and stable adhesion contacts between neighbour fiber cells acting as rigid intercellular pickets or lineactants to maintain the junctional role of the more flexible $\left(\kappa_{\mathrm{c}}=1560 k_{\mathrm{B}} T\right.$, table S1), 45 fragile and subtle assembly of AQP0 microdomains. During accommodation and to ensure microcirculation, neighbour fiber cells from the eye lens are subjected to pressure differences. Our data allows us to estimate the deformation due to this pressure. Assuming a difference in pressure between cells of $20 \mathrm{kPa}$ (the ${ }_{50}$ Young's modulus of eye lens nuclear fiber $\operatorname{cells}^{38}$ ) the deformation expected for AQP0 domains was of only $\sim 0.3 \mathrm{~nm}$ for $100-\mathrm{nm}$ diameter domains, but up to $5 \mathrm{~nm}$ for $200-\mathrm{nm}$ radius domains (see Supporting Information). Thus, lack of rigid and stable adhesion points, as found in congenital and diabetes II ${ }_{55}$ cataract membranes ${ }^{22,39}$, would lead to excessive deformation, leading to breakage of AQP0 junctional microdomains, increase of intercellular space and cataract formation. The remarkable stability and rigidity of gap junctions in the eye lens suggests them as force bearing adhesion complexes, functioning as force 60 transducers between neighboring cells during accommodation. The more flexible AQP0 domains would undergo considerable deformation allowing pressure release.

The elasticity of the individual proteins revealed signatures of ${ }_{65}$ their structure-function relationship. The CP surface of AQP0 was on average significantly more compliant than the EC face. This may be a result of the more compact arrangement of the short AQP0 EC loops evolved to engage in the homotypic junction formation, compared to the $\mathrm{CP}$ face with longer $\mathrm{CP}$ 70 loops and the free-standing $\mathrm{N}$ - and C-termini ${ }^{40}$. However, the compliant $\mathrm{CP}$ surface of $\mathrm{APQ} 0$ appears to emerge from the lack of contact with the mica surface of thin junctions. In the case of connexons, in both configurations with either EC or CP exposed, the proteins are supported by the mica substrate. Thus, we are in ${ }_{5}$ position of comparing the stiffness of the two regions. The EC surface of connexons appeared stiffer than the CP surface, in agreement with the estimated temperature factors from crystallographic analysis ${ }^{41}$. This reflects the rigid conformation of the Cx EC loops, probably due to the disulfide bonded beta ${ }_{80}$ strands, compared to the yet unsolved, much larger and probably less structured CP tail of lens $\mathrm{Cx}{ }^{41,42}$. This differential stiffness of $\mathrm{Cx}$ is related to the different functions of the two faces, channel gating through a more flexible cytoplasmic plug, and adhesion and force-bearing role of the rigid extracellular ${ }_{85}$ domains. Unlike temperature factors, our elastic maps allow us to compare the relative rigidity of the two proteins. The similarly high $E$ values of EC connexons and AQP0s may reflect a common feature of the binding domains of proteins.

${ }_{90}$ On domains solely occupied by AQP0s or connexons, the distribution of $E$ values allows us to estimate the ratio of occupied area of protein to lipid (Fig. S3). From bimodal Gaussian fits to the distribution of $\log (E)$ values of AQP0 regions on both $\mathrm{CP}$ and $\mathrm{EC}$ faces, we calculated that the AQP0/lipid area 95 ratio was of $\sim 4$. This is close to the expected ratio of 3.7 calculated by knowing that there are 9 annular lipids per AQP0 monomer ${ }^{40}$, the estimated area occupied per lipid ${ }^{43}$ and the unit cell size of AQP0 tetramer lattices. This remarkable precision suggests that elasticity maps provide information about the 100 nanoenvironment of membrane proteins. In the case of connexons, the protein/lipid area ratios were remarkably different for the CP and EC surfaces. On the EC surface it was $\sim 9$, implying that there is less accessible lipids between connexons than between AQP0 tetramers. On the CP surface, the ratio was 105 even higher $(\sim 49)$, even if the number of surrounding lipids is similar. This unreasonable ratio suggests that the CP domains of $\mathrm{Cx}$ proteins span over much larger lateral areas than EC ones, in accordance with the conical tsuzumi ${ }^{\ddagger}$ shape of the crystal structure of $\mathrm{Cx} 26^{41}$. It is important to note that lens membranes 110 from the nuclear bovine eye lens contain mainly two types of connexin, $\mathrm{Cx} 44$ and $\mathrm{Cx} 49$ (homologous to human $\mathrm{Cx} 46$ and Cx50). Unlike Cx26, shown in figure 1 and the only structure of a connexin solved to date, lens Cxs present much larger cytoplasmic domains of $\sim 15 \mathrm{kDa}^{44}$. Thus, our results suggest that 115 the CP surface of Cxs cover almost all the CP surface area, 
burying the surrounding lipids, and adopting very close packing of the CP domains of connexons, perhaps forming actual contacts.

5 As presented in Table 1, the elasticity of lipids surrounding AQP0 or connexons was remarkably higher than that of isolated lipids. Although mechanical perturbation of the proteins themselves cannot be excluded, this suggests two possibilities. One, that the protein-associated lipids are mechanically more 10 stable and less mobile than isolated ones due to the more crowded nanoenvironment. And two, that protein associated lipids are of a different species than isolated ones. Interestingly, there is strong evidence that AQP0 recruit and tightly bind cholesterol and sphingomyelin present in the eye lens membrane and form, 15 together with these, detergent resistant membranes ${ }^{45}$, reported to be up to three times stiffer than pure phospholipid domains ${ }^{35}$. These results imply that the mechanical stability of the plasma membrane is not only due to the mechanical properties of the individual components, but also modulated by their 20 supramolecular organization.

The eye lens is a remarkable tissue that must assure two functions. On the one hand, it must be deformable, allowing accommodation when focusing at different distances throughout 25 the human lifespan. On the other hand, it must preserve a tight and solid cell packing to distances inferior to the wavelength of visible light for being transparent. Therefore, the eye lens requires cell-cell junctions capable of transmitting forces and withstanding pressure changes from one cell to the other to allow ${ }_{30}$ deformation, and close proximity between cells to avoid light scattering. Indeed, lenses with compromised cytoskeleton but intact cell-cell adhesion have shown to preserve transparency ${ }^{46}$, which reflects the importance of proper cell contacts. Our data suggests that the more rigid gap junctions would effectively carry

35 out this first biomechanical function by maintaining firm cell-cell contact, while serving as stable lateral support to the more flexible AQP0 thin junctions that would assure close proximity between adjacent plasma membranes and provide flexibility to allow pressure release. We could speculate that the normal 40 deformation of AQP0 domains will increase membrane tension, in turn modulating water conductance.

In summary, we present direct evidence of the mechanical heterogeneity of the components, nanoenvironment and 45 supramolecular assembly of the plasma membrane of lens fiber cells. Given the observed crowdedness of other plasma membranes, we propose that this mechanical heterogeneity is not particular to fiber cells from the eye lens but instead found in every plasma membrane. Therefore, the mechanics of membrane so proteins provides an essential and specific signature associated to biological function.
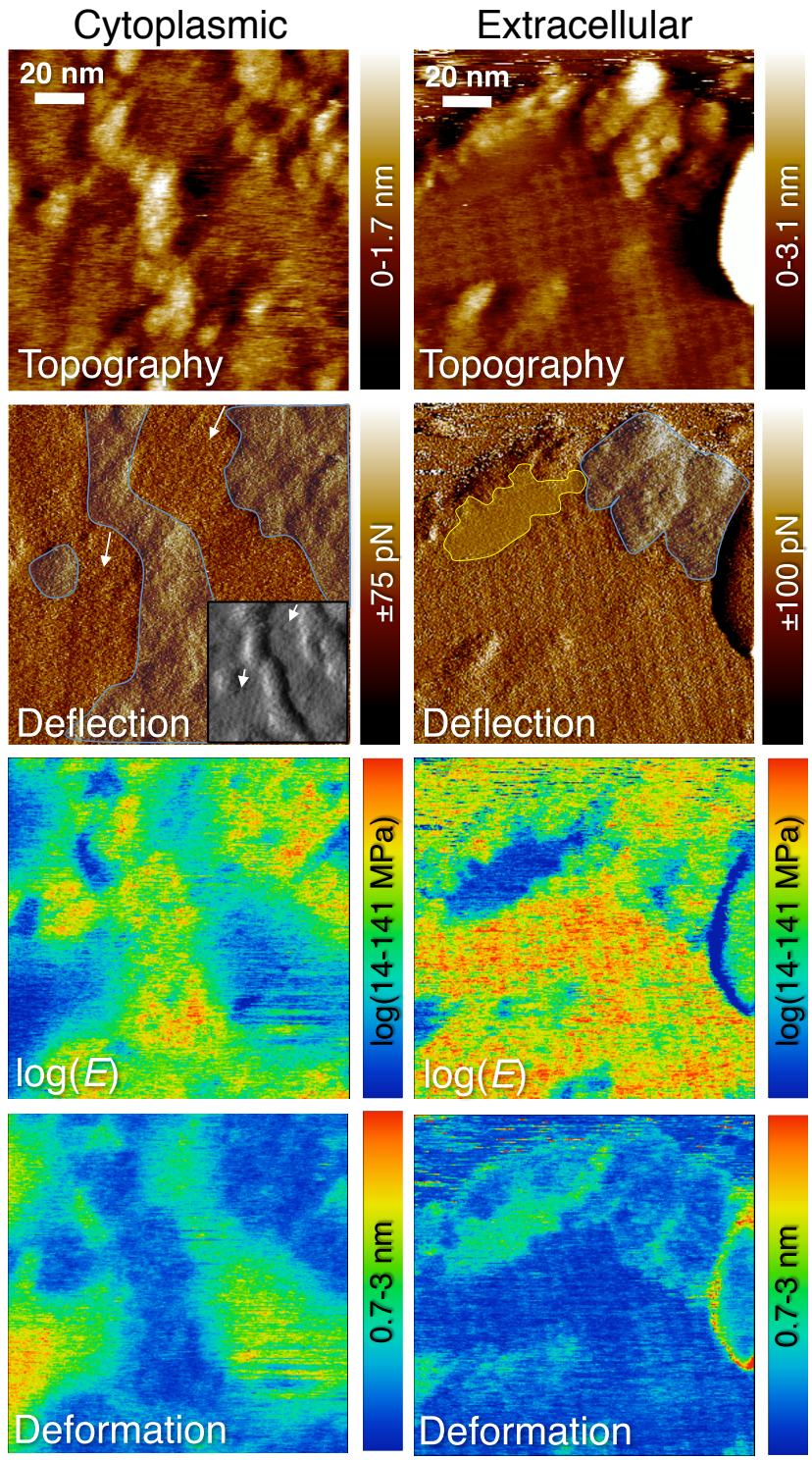

Fig. 3 Mechanical properties of individual membrane proteins. Left) maps 55 of the cytoplasmic (top layer) surface. The inset in deflection shows the same region of the bottom layer after nanodissection, revealing the same AQP0 orientation (arrows). Right) extracellular face (bottom layer) revealing the square array formed by $\mathrm{AQP} 0$ tetramers and ring-like connexons with visible central pore. Shaded areas in the deflection images show $\mathrm{Cx}$ (blue) and lipid domains (yellow). Unabeled areas represent AQP0 domains. The regions shown are those delimited by dotted squares in Fig. 2
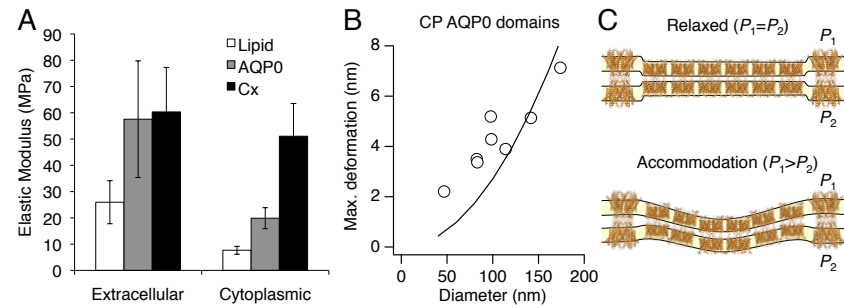

Fig. 4 Quantitative mechanics of eye lens membranes. A) Average mean ( \pm standard deviation) obtained from regions presenting either molecular species. B) Maximum deformation of aquaporin 0 (AQP0) thin 
junctions as a function of domain diameter (open circles). The solid line is not a fit to the experimental data but the prediction assuming thin plate theory using the Young's modulus of extracellular AQP0 ( $E=58 \mathrm{MPa})$ and 10-nm thickness of AQP0 thin junctions (see Eq. S2 in Supporting

5 Information). C) Deformation mechanism of the lens membrane due to pressure difference between neighbour cells.

\section{Experimental procedures}

\section{Lens membrane preparation and immobilization}

10 Native membranes were isolated from nuclear fiber cells from ovine eye lenses after removal of the cortical shell as previously described ${ }^{19,47}$. Lens membranes were immobilized on a freshly cleaved mica surface for 10 min by adding $\sim 3 \mu \mathrm{L}$ in $40 \mu \mathrm{L}$ of adsorption buffer (10 mM Tris- $\mathrm{HCl}(\mathrm{pH} 7.4), 150 \mathrm{mM} \mathrm{KCl}, 25$

$15 \mathrm{mM} \mathrm{MgCl}_{2}$ ) at room temperature and then rinsed with measurement buffer (10 mM Tris- $\mathrm{HCl}$ (pH 7.4), $150 \mathrm{mM} \mathrm{KCl})$.

\section{AFM measurements}

AFM measurements were carried out in measurement buffer at room temperature and ambient pressure on a Nanoscope-V AFM

20 (Bruker, Santa Barbara, CA) equipped with Nanoscope 8 control software, in PeakForce and contact modes. We used $\mathrm{Si}_{3} \mathrm{~N}_{4}$ cantilevers with nominal spring constant of $100 \mathrm{pN} / \mathrm{nm}$ or 500 $\mathrm{pN} / \mathrm{nm}$ and silicon tips with 2-nm nominal radius (MSNL, Bruker, Santa Barbara, CA). The spring constant of the ${ }_{25}$ cantilevers was calibrated using the thermal fluctuations method before the measurements ${ }^{48}$.

PeakForce imaging mode consisted of oscillating the sample support at constant rate $(2 \mathrm{kHz})$ and amplitude (between 5 and 30 $\mathrm{nm}$ ). During each oscillation cycle, the deflection (force) of the

30 cantilever was monitored to obtain a force-distance curve. The vertical amplitude of the piezoelectric displacement was set to allow the tip to completely separate out of contact from the sample surface, allowing accurate determination of the zero force and the maximum applied indentation force (Fig. S1). The 35 approach trace was used to control the maximum force applied $(\sim 300 \mathrm{pN})$ and the deformation. The retraction regime was used to determine the Young's modulus. Images were obtained at a resolution of 256 by 256 pixels (Figs. 2A, 2B and 2C and Fig. 3) or 512 by 512 pixels (Figs. 1B and 2D) at scan rates of $2 \mathrm{~Hz}$ and $401 \mathrm{~Hz}$, respectively. The Young's modulus $(E)$ was calculated at each pixel of the image from the contact part of the retraction trace of each oscillation cycle by fitting the Hertz model of a spherical tip of radius $R$ indenting an elastic half-space ${ }^{8,49}$

$$
F=\frac{4 E}{3\left(1-v^{2}\right)} \sqrt{R} \delta^{3 / 2}
$$

${ }_{45}$ being $v=0.5$ the Poisson ratio and $\delta$, the indentation. The radius of the tip was assumed to be $2 \mathrm{~nm}$, its nominal value.

To avoid the contribution of the long-range forces coming from electrostatic and van del Waals interactions, we restricted the fit to a range between $5 \%$ and $70 \%$ of the maximum indentation

50 force. The deformation was calculated as the indentation range corresponding to the $85 \%$ of the maximum force of the approach curve (SI).

\section{Nanodissection of lens membranes}

Nanodissection of the top layer of lens membrane was carried out 55 in contact mode. During imaging (scan rate $5 \mathrm{~Hz}$ ) of the whole membrane fragment including the surrounding mica substrate, the imaging setpoint was increased until physical removal of the top layer took place (at around and above $200 \mathrm{pN}$ of applied force) ${ }^{29}$.

\section{Image analysis}

60 Images were analyzed using Gwyddion 2.26 software (http://gwyddion.net). Average values of the Young's modulus of $\mathrm{CP}$ and EC AQP0, Cx and lipid domains were obtained from at least 3 regions from one sample of double-layered, $\mathrm{CP}$-exposing membranes and from 5 samples of single-layered, EC-exposing 65 membranes.

The diameter of the AQP0 domains was determined by measuring the area of each domain and assuming circular shape, thus Diameter $=2 \sqrt{\text { Area } / \pi}$.

To obtain detailed insight into the mechanical properties of the 70 individual proteins and the associated lipids, we computed histograms of the logarithm of $E$ of masked regions presenting only either AQP0 or $\mathrm{Cx}$ from both $\mathrm{EC}$ and $\mathrm{CP}$ faces (supplementary Fig. S3). Histograms were well fitted with bimodal Gaussian functions corresponding to the two main 75 elasticity populations, one of protein associated lipids and one of proteins (Igor Pro 6, Wavemetrics, Oswego, OR). 
Table 1. Elasticity of individual proteins and protein-associated lipids. Young's modulus $(E)$ and relative areas obtained from bimodal Gaussian fits to the stiffness distributions for extracellular and cytoplasmic domains presenting either only APQ0 or Cx proteins (see Fig. S3). For comparison, the average $E$ values for $\mathrm{CP}$ and EC lipid domains are shown in the bottom row.

\begin{tabular}{|c|c|c|c|c|c|}
\hline & & \multicolumn{2}{|c|}{ Cytoplasmic } & \multicolumn{2}{|c|}{ Extracellular } \\
\hline & & $E(\mathrm{MPa})$ & Area $(\%)$ & $E(\mathrm{MPa})$ & Area \\
\hline \multirow{2}{*}{ AQP0 domains } & AQP0 & 22 & 80 & 58 & 81 \\
\hline & AQP0- associated lipid & 16 & 20 & 29 & 19 \\
\hline \multirow{2}{*}{ Cx domains } & $\mathrm{Cx}$ & 40 & 98 & 68 & 89 \\
\hline & Cx-associated lipid & 19 & 2 & 32 & 11 \\
\hline Lipid domains & & 8 & 100 & 26 & 100 \\
\hline
\end{tabular}

\section{Acknowledgements}

10 This study was supported by the Institut National de la Santé et Recherche Médicale (INSERM) and the Agence Nationale de la Recherche (ANR, Project \# ANR-12-BSV8-0006-01).

\section{References}

15 1. 1. D. M. Engelman, Nature, 2005, 438, 578-580.

2. R. L. Juliano, Annu. Rev. Pharmacol. Toxicol., 2002, 42, 283-323.

3. R. O. Hynes, Trends Cell Biol., 1999, 9, M33-M37.

4. S. H. Chung, O. S. Anderson and V. V. Krishnamurthy, Biological Membrane Ion Channels: Dynamics, Structure, and Applications, Springer, 2010.

5. M. Dong, S. Husale and O. Sahin, Nat Nanotechnol, 2009, 4, 514517.

6. I. Mey, M. Stephan, E. K. Schmitt, M. M. MuÃàller, M. Ben Amar, C. Steinem and A. Janshoff, J. Am. Chem. Soc., 2009, 131, 70317039.

7. F. Rico, C. Su and S. Scheuring, Nano Lett., 2011, 11, 3983-3986.

8. L. Picas, F. Rico and S. Scheuring, Biophys. J., 2012, 102, L01-L03.

9. D. Martinez-Martin, E. T. Herruzo, C. Dietz, J. Gomez-Herrero and R. Garcia, Phys. Rev. Lett., 2011, 106, 198101.

30 10. I. Medalsy, U. Hensen and D. J. Muller, Angew. Chem. Int. Ed., 2011, 50, 12103-12108.

11. R. P. Goncalves, G. Agnus, P. Sens, C. Houssin, B. Bartenlian and S. Scheuring, Nat Meth, 2006, 3, 1007-1012.

12. N. Q. Balaban, U. S. Schwarz, D. Riveline, P. Goichberg, G. Tzur, I.

35 Sabanay, D. Mahalu, S. Safran, A. Bershadsky, L. Addadi and B. Geiger, Nat. Cell Biol., 2001, 3, 466-472.

13. V. Vogel and M. Sheetz, Nat Rev Mol Cell Biol, 2006, 7, 265-275.

14. R. Phillips, T. Ursell, P. Wiggins and P. Sens, Nature, 2009, 459, 379-385.

40 15. G. Zaccai, Science, 2000, 288, 1604-1607.

16. S. Song, A. Landsbury, R. Dahm, Y. Liu, Q. Zhang and R. A. Quinlan, The Journal of Clinical Investigation, 2009, 119, 1837 1848 .

17. J. Alcala, N. Lieska and H. Maisel, Exp. Eye Res., 1975, 21, 581-595.

45 18. G. Zampighi, S. A. Simon, J. D. Robertson, T. J. McIntosh and M. J. Costello, The Journal of Cell Biology, 1982, 93, 175-189.

19. N. Buzhynskyy, R. K. Hite, T. Walz and S. Scheuring, EMBO Rep, 2007, 8, 51-55.

20. N. Buzhynskyy, J. F. Girmens, W. Faigle and S. Scheuring, J. Mol. Biol., 2007, 374, 162-169.

21. J. Liu, J. Xu, S. Gu, B. J. Nicholson and J. X. Jiang, J. Cell Sci., 2010, 124, 198-206.

22. N. Buzhynskyy, P. Sens, F. Behar-Cohen and S. Scheuring, New J. Phys., 2011, 13, 16.

55 23. T. Gonen, P. Sliz, J. Kistler, Y. Cheng and T. Walz, Nature, 2004, 429, 193-197.
24. W. E. C. Harries, D. Akhavan, L. J. W. Miercke, S. Khademi and R. M. Stroud, Proc. Natl. Acad. Sci. U. S. A., 2004, 101, 14045-14050.

25. M. O. Jensen, R. O. Dror, H. Xu, D. W. Borhani, I. T. Arkin, M. P.

60 Eastwood and D. E. Shaw, Proc. Natl. Acad. Sci. U. S. A., 2008, 105, 14430-14435.

26. M. L. Cotrina, J. H. Lin and M. Nedergaard, Glia, 2008, 56, 17911798.

27. L. A. Elias, D. D. Wang and A. R. Kriegstein, Nature, 2007, 448, 901-907.

28. F. Rico, A. Oshima, P. Hinterdorfer, Y. Fujiyoshi and S. Scheuring, J. Mol. Biol., 2011, 412, 72-79.

29. S. Scheuring, J. Seguin, S. Marco, D. Levy, B. Robert and J. L. Rigaud, Proc. Natl. Acad. Sci. U. S. A., 2003, 100, 1690-1693.

70 30. D. Fotiadis, L. Hasler, D. J. M $\vee^{\circ} 1$ ler, H. Stahlberg, J. r. Kistler and A. Engel, J. Mol. Biol., 2000, 300, 779-789.

31. E. L. Benedetti, I. Dunia and H. Bloemendal, Proceedings of the National Academy of Sciences, 1974, 71, 5073-5077.

32. R. Bruinsma, A. Behrisch and E. Sackmann, Physical Review E, 2000, 61, 4253-4267.

33. T. R. Weikl, M. Asfaw, H. Krobath, B. Rozycki and R. Lipowsky, Soft Matter, 2009, 5, 3213-3224.

34. W. Rawicz, K. C. Olbrich, T. McIntosh, D. Needham and E. Evans, Biophys. J., 2000, 79, 328-339.

80 35. E. Sackmann, R. Lipowsky and E. Sackmann, in Handbook of Biological Physics, North-Holland, 1995, vol. Volume 1, pp. 213304.

36. H. Bloemendal, A. Zweers, F. Vermorken, I. Dunia and E. L. Benedetti, Cell Differ., 1972, 1, 91-106.

85 37. L. D. Landau and E. M. Lifshitz, Theory of Elasticity, Pergamon Press, Oxford, 1986.

38. A. Hozic, F. Rico, A. Colom, N. Buzhynskyy and S. Scheuring, Invest. Ophthalmol. Vis. Sci., 2012, 53, 2151-2156.

39. S. Mangenot, N. Buzhynskyy, J. F. Girmens and S. Scheuring, Pflugers Arch., 2009, 457, 1265-1274.

40. T. Gonen, Y. F. Cheng, P. Sliz, Y. Hiroaki, Y. Fujiyoshi, S. C. Harrison and T. Walz, Nature, 2005, 438, 633-638.

41. S. Maeda, S. Nakagawa, M. Suga, E. Yamashita, A. Oshima, Y. Fujiyoshi and T. Tsukihara, Nature, 2009, 458, 597-602.

95 42. A. Oshima, K. Tani, Y. Hiroaki, Y. Fujiyoshi and G. E. Sosinsky, Proc. Natl. Acad. Sci. U. S. A., 2007, 104, 10034-10039.

43. R. S. Cantor, Biophys. J., 1999, 76, 2625-2639.

44. M. Yeager, in Connexins, 2009, pp. 27-75.

45. J. Tong, M. M. Briggs, D. Mlaver, A. Vidal and T. J. McIntosh, Biophys. J., 2009, 97, 2493-2502.

46. R. B. Nowak, R. S. Fischer, R. K. Zoltoski, J. R. Kuszak and V. M. Fowler, The Journal of Cell Biology, 2009, 186, 915-928.

47. T. Gonen, Y. Cheng, J. Kistler and T. Walz, J. Mol. Biol., 2004, 342, 1337-1345.

105 48. J. L. Hutter and J. Bechhoefer, Rev. Sci. Instrum., 1993, 64, 18681873.

49. H. Hertz, in Hertz's Miscellaneous Papers, Macmillan, London, 1881, pp. 146-162. 


\section{Notes and references}

${ }^{a}$ U1006 INSERM, Aix-Marseille Université, Parc Scientifique de Luminy, 13009 Marseille, France. Fax: ++33 (0)4 918287 01; Tel: ++33 (0)4

918287 00; E-mail: simon.scheuring@inserm.fr

$5^{b}$ Institut Curie, UMR144 CNRS, 26 rue d'Ulm, 75005 Paris, France

$\dagger$ Electronic Supplementary Information (ESI) available: Methods, supporting figures and supporting table. See DOI: 10.1039/b000000x/

$\ddagger$ traditional Japanese drum 